\title{
Impact of humor-related communication elements in natural dyadic interactions on interpersonal physiological synchrony
}

\author{
Helmut K. Lackner ${ }^{1}$ (D) | Kurt Feyaerts $^{2}$ | Christian Rominger $^{3}$ | \\ Bert Oben $^{2}$ | Andreas Schwerdtfeger ${ }^{3}$ (D) | Ilona Papousek ${ }^{3}$ (I)
}

${ }^{1}$ Division of Physiology, Otto Loewi Research Center, Medical University of Graz, Graz, Austria

${ }^{2}$ Department of Linguistics, University of Leuven, Leuven, Belgium

${ }^{3}$ Institute of Psychology, University of Graz, Graz, Austria

\section{Correspondence}

Helmut K. Lackner. Division of Physiology, Otto Loewi Research Center, Medical University of Graz, Neue Stiftingtalstrasse 6/ D 05, A-8010 Graz, Austria.

Email: helmut.lackner@medunigraz.at

\begin{abstract}
Evidence suggests that in dyadic conversations some alignment occurs at the physiological level, but relatively little is known about the conditions that may facilitate physiological synchrony of two interlocutors. In the present interdisciplinary study, the impact of specific linguistic features of ongoing dialogues - the use of humor-related communication elements-was examined in 24 male dyads who were meeting for the first time. Heart rate synchrony was quantified using phase synchronization, which reflects the degree of moment-to-moment adjustments that occur between the two persons of a dyad. Comical hypotheticals and verbal amplifiers were identified and quantified using cognitive-linguistic methods of corpus analysis. Additionally, smiles following these communication elements were identified using the Facial Action Coding System. The data showed that the heart rate time series of the two interlocutors were to some extent synchronized in phase, and that the magnitude of this synchronization exceeded what had to be expected by chance. The strength of heart rate synchrony in a dyad was the higher the more comical hypotheticals were produced, independently from how much the two conversation partners were in sum talking to each other. A similar observation was made for verbal amplifiers, but their effect depended on whether they were perceived (and acknowledged by a smile) as humorous. The findings are in line with the more general notion that physiological synchrony may be enhanced by shared experience and suggest that the use of (reciprocated) humor may speed up the building of rapport among communication partners.
\end{abstract}

\section{K E Y W O R D S}

corpus linguistics, dyadic interactions, heart rate, interactive alignment, interpersonal physiology,

physiological synchrony

\section{1 | INTRODUCTION}

Dyadic conversation can be understood as a joint activity, where the interlocutors collaborate to establish a joint understanding of their conversational content (Clark, 1996). Interlocutors continuously align their linguistic and behavioral construal with what they assume to be in the minds of their conversational partners. Accordingly, conversation is an interpersonal action that requires constant adjustment and negotiation among intersubjective viewpoints (Feyaerts \& Oben, 2014; Verhagen, 2015). These processes are accompanied by interactive alignment at many different levels (Chartrand \& Lakin, 2013; Garrod \& Pickering, 2004), manifested, for instance, in lexical repetitions (Brennan \& Clark, 
1996), linguistic style matching (Feyaerts, Oben, Lackner, \& Papousek, 2017), convergence in intonation (Gorisch, Wells, \& Brown, 2012), grammatical constructions (Gries, 2005), and pronunciation (Pardo, 2006), as well as in the alignment of posture (Paxton \& Dale, 2013), gestures (Holler \& Wilkin, 2011), and gaze behavior (Oben \& Brône, 2015, 2016; Richardson \& Dale, 2005).

Beyond these openly noticeable forms of mutual synchronization of conversation partners, there is evidence that some alignment also occurs at the physiological level (see Palumbo et al., 2017, for a recent review). Physiological synchrony refers to similarities in two persons' physiological dynamics during social interaction. It occupies a special position in the broader field of interpersonal alignment as compared to behavioral forms of synchrony, because it is manifested beyond individuals' awareness and voluntary control. Moreover, physiological synchrony captures interaction partners' mutual adaptation of mental processes and internal states, which may not manifest in the synchronization of open behavior that can be obtained by behavioral observation. Hence, it is viewed as a valuable objective and sensitive indicator related to the building of rapport among communication partners.

Basically, physiological synchrony can be assessed using any physiological measure that is collected from two individuals over time. However, findings may vary with the physiological measures obtained (Palumbo et al., 2017), putatively depending, among other factors, on how sensitive the physiological system responds to relevant psychosocial processes. In the present article, we focus on heart rate synchrony. Transient changes of heart rate index the net effects of fast sympathetic and parasympathetic inputs to the sinus node (Goldberger, 1999) and represent a sensitive, flexible, and rapidly responding system in the context of psychophysiological adaptations. Transient heart rate changes (occurring on the scale of a few heartbeats) go along with subtle changes in ongoing psychological demands and contexts that are linked with rapid, fleeting changes of emotional arousal and motivational states (e.g., Bradley, Codispoti, Cuthbert, \& Lang, 2001; Gunther Moor, Crone, \& van der Molen, 2010; Lackner et al., 2013; Papousek, Aydin, et al., 2014; Papousek, Weiss, et al., 2014; Wright \& Gendolla, 2012).

It has been demonstrated that the mere presence of one's romantic partner may be a sufficient elicitor of some degree of heart rate synchrony (Helm, Sbarra, \& Ferrer, 2012). However, research suggests that the strength or "magnitude" of physiological synchrony may be enhanced by some kind of shared experience, both among acquaintances and strangers (Palumbo et al., 2017). This may be manifested in diffuse constructs such as empathy (Järvelä, Kivikangas, Kätsyri, \& Ravaja, 2013) or feelings of greater involvement in the social interaction (Chanel, Kivikangas, \& Ravaja, 2012) as well as more experimental and behavioral indicators. For instance, greater magnitudes of heart rate synchrony were associated with a stronger focus on/less distraction from the interaction partner (Coleman, Greenblatt, \& Solomon, 1956), more conflict-laden marital interactions (Levenson \& Gottman, 1983), increasing trust building between the interacting persons (Mitkidis, McGraw, Roepstorff, \& Wallot, 2015), and better performance in a task requiring collaboration (Henning, Boucsein, \& Gil, 2001; Henning \& Korbelak, 2005).

Nonetheless, the question of which conditions facilitate heart rate synchrony between two conversational partners still remains largely unanswered (Goldstein, WeissmanFogel, \& Shamay-Tsoory, 2017). In particular, this observation applies to naturally occurring conversations, which are nonscripted and not determined by any joint task, and to dyads meeting for the very first time. As with physiological synchrony in general, most previous research on heart rate synchrony was concerned with attachment relationships such as mother-child (Feldman, Magori-Cohen, Galili, Singer, \& Louzon, 2011; Field, Healy, \& LeBlanc, 1989; Suveg, Shaffer, \& Daavis, 2016; Woltering, Lishak, Elliott, Ferraro, \& Granic, 2015), therapist-client (Coleman et al., 1956), and romantic couples (Ferrer \& Helm, 2013; Levenson \& Gottman, 1983). Analyses of dyads of individuals previously unknown to each other have been scarce to date (Mitkidis et al., 2015). Moreover, to the best of our knowledge, to date there have been no attempts to link the magnitude of heart rate synchrony between two interlocutors with linguistic features of the ongoing dialogue. In this context, we focused on humor.

In dyadic encounters, humor functions to indicate interest in initiating a social relationship and aids its formation and maintenance. Shared humor increases involvement in the dialogue and feelings of connectedness and closeness between the interaction partners (Curry \& Dunbar, 2013; Fraley \& Aron, 2004; Kashdan, Yarbro, McKnight, \& Nezlek, 2014; Kurtz \& Algoe, 2015; Li et al., 2009; Weisfeld, 1993). One way to introduce humor in a free, spontaneous conversation is in the form of comical hypotheticals, in which conversation partners fantasize about funny, imaginary experiences, based on the actual situation in which the communication takes place (Feyaerts, 2013; Winchatz \& Kozin, 2008). Throughout a conversation, interlocutors typically produce a similar amount of comical hypotheticals; that is, the incidences of comical hypotheticals in one speaker are positively correlated with those of the other speaker in a dyad (Feyaerts et al., 2017). The use of comical hypotheticals in a dialogue indicates, among other things, that interlocutors judge their conversation partners not objecting to or even positively willing to participate in the use of this type of humor. Incorporating processes of interpersonal viewpoint and mentalizing, the use of comical hypotheticals can be seen as a manifestation of involvement in the social interaction.

A second linguistic category related to humor (albeit more remotely) is represented by so-called verbal amplifiers. 
Verbal amplifiers (or also "intensifiers"; Breindl, 2007; Gutzman \& Turgay, 2012) refer to the expression of heightened degree and intensity such as super, totally, incredibly, etc., and, in a spontaneous conversation, are often used to exaggerate something in a humorous or ironic way (Hancock, 2004). Amplifiers open up a window onto a speaker's evaluative stance and, thus, can play an important role in the interactive process of mutual adjustment of intersubjective viewpoints through which a joint understanding of the conversational content is eventually established. Compared to comical hypotheticals, amplifiers are less interactive in nature, but they are also considered to indicate involvement in the social interaction (Athanasiadou, 2007). Corroborating this notion and their relation to familiarity and connectedness, empirical data showed that, when one interlocutor's use of amplifiers increases over the course of a spontaneous conversation, the conversation partner tends to use increasingly more amplifiers as well (Feyaerts et al., 2017).

The main research question in the present interdisciplinary study was whether the quantities of these humor-related communication elements in the conversation of a dyad were correlated with the magnitude of heart rate synchrony between the two interlocutors, beyond the overall degree of communicativeness of the dyad. That is, the study was concerned with the question of whether the heart rates of two communication partners may be more synchronized when humor-related communication elements are used in their conversation to a greater extent.

We studied male dyads whose members had never met before the beginning of their conversation. The situation building the ground for the conversation was set up by seating the two partners of a dyad facing one another and keeping them waiting for about $20 \mathrm{~min}$, telling them twice that the experiment for which they were scheduled would start "any moment now". The waiting situation was chosen because it did not necessarily prompt the production of humor but allowed also for humorous exchanges. That way, many types of exchanges were possible, which permitted adequate variability in the use of humorous communication elements among the dyads. The participants were not occupied with anything and were free in what they were talking about. The magnitude of heart rate synchrony was quantified using phase synchronization, a method adopted from the analysis of loosely coupled chaotic oscillators, which is unaffected by nonstationarity of the heart rate time series. The degree of phase synchronization reflects the degree of moment-to-moment adjustments that occur between the two persons of a dyad. The detection of heart rate synchrony was validated by comparing the data from actual dyads with data from all possible pairs of participants in the sample excluding the actual dyads. It was further examined whether matched breathing or motor behavior may have been drivers of heart rate synchrony.
Comical hypotheticals and verbal amplifiers were identified and quantified using cognitive-linguistic methods of corpus analysis. Finally, to additionally quantify and take into account the importance of the reception of humor and its acknowledgment in the comical hypotheticals and verbal amplifiers produced by the other person in a dyad, facial expressions of smiles following these communication elements were identified using the Facial Action Coding System (FACS AU 12; Ekman, Friesen, \& Hager, 2002). Thereby, it could be examined whether the amount of displays of the reception of humor may explain additional variance of the magnitude of heart rate synchrony in a conversation dyad. The study focused on dyads (as opposed to larger groups) because conversations are most typically dyadic, and the theoretical linguistic accounts underlying the study are almost exclusively based on dyadic conversation.

It was hypothesized that the heart rate time series of conversation partners would to some degree be synchronized in phase, and that the magnitude of this heart rate synchronization would be higher when humor-related communication elements (comical hypotheticals, amplifiers) were used in a conversation to a greater extent. It was further hypothesized that the magnitude of heart rate synchrony may be additionally increased if interlocutors showed more displays of the reception of humor in comical hypotheticals or amplifiers produced by their conversation partner.

\section{$2 \mid$ METHOD}

\section{1 | Participants}

The sample comprised 48 male university students who were enrolled in various fields (19 natural/technical sciences, 10 law/business, 7 language/linguistics, 3 informatics, 3 history/political sciences, 2 health sciences, 2 archaeology, 1 psychology, 1 arts). Their age was between 18 and 38 years $(M=23, S D=4)$. Two participants who had not met each other prior to the experiment were grouped into dyads ( $n=24$ dyads). Individuals who reported using psychoactive medication or medication affecting the cardiovascular system were not included in the study. A men-only sample was chosen to avoid the introduction of additional error variance caused by differences in the flexibility of heart rate fluctuations that are associated with the menstrual cycle status and are also related to women's sensitivity to social-emotional signals (Muhtadie, Akinola, Koslov, \& Mendes, 2015; Sato \& Miyake, 2004; Tenan, Brothers, Tweedell, Hackney, \& Griffin, 2014). The study was performed in accordance with the American Psychological Association's Ethics Code and the Declaration of Helsinki and was approved by the authorized ethics committee. All participants gave written consent to participate in the study, to be filmed for scientific purposes, and their data to 
be used for the scientific purposes of the study. They were reimbursed for their participation with two cinema tickets each and were informed in detail about the purposes of the experiment after completion of the study.

\section{2 | Procedure}

Participants were invited to participate in a cartoon-rating experiment using flyers and posters distributed around the campus. The cartoon rating was used only as the cover story. Having the participants wait for the alleged experiment provided time for free conversation between the members of a dyad, setting up a standardized ground for the conversation without occupying them by a task. Data acquired in the waiting period were used for the synchrony analysis.

After electrodes were attached, the two partners of a dyad were seated facing one another, with a computer monitor on their left-/right-hand side that showed the time of day throughout the interactive part of the experiment. Mobile phones were turned off and stowed away. Participants rated their momentary anger and joyousness on standardized 17point rating scales ranging from 1 (none) to 17 (extremely strong; KUSTA; Binz \& Wendt, 1986). Then, they were instructed regarding the alleged cartoon ratings, were asked to stay seated because the experiment could start at any moment, and were told that a tone would signal the beginning of the presentation of the cartoons, which would be shown on the monitor. They were told that the rating task would start only after the principal investigator had controlled the equipment and quality of the video recordings. At that point, the experimenter left the room. After $7.5 \mathrm{~min}$, the experimenter returned and asked the participants whether the experiment had already started. After the participants answered in the negative, the experimenter promised to look for the principal investigator. After another $7.5 \mathrm{~min}$ had elapsed, the experimenter returned again, told the participants that she now had reached the principal investigator, and that she would arrive soon. After another $7.5 \mathrm{~min}$, the experimenter entered the room, apologized for the inconvenience, and manually started the presentation of the cartoons $(2 \mathrm{~min}$ ). Then, the participants rated the cartoons (data not used) and completed the anger and joyousness ratings again.

In addition to the electrocardiogram (ECG) recording, participants were filmed throughout the waiting period with four high quality cameras, two cameras recording full-length portraits and two cameras recording close-up views, suitable for the transcription of conversations and FACS analysis.

\subsection{Heart rate synchrony}

The ECG was recorded continuously using a portable device (Varioport, Becker Meditec, sampling rate $=256 \mathrm{~Hz}$ ). The disposable electrodes were placed at the thoracic region (corresponding to Einthoven Lead II). For detection of the $\mathrm{R}$ wave, the raw signals were oversampled using a cubic spline function in the surrounding of the first detection of the $\mathrm{R}$ wave resulting in a sampling rate of $1,024 \mathrm{~Hz}$, and the heart rate was calculated from the RR interval. To obtain heart rate time series with equidistant time steps, the beat-to-beat values were resampled at $4 \mathrm{~Hz}$, using piecewise cubic spline interpolation after semiautomatic artifact correction. Single artifacts were replaced by interpolation (e.g., Lackner, Batzel, Rössler, Hinghofer-Szalkay, $\&$ Papousek, 2014).

Heart rate synchrony, that is, synchronization of the heart rates of the two interaction partners in a dyad, was determined by the analysis of phase synchronization. The analysis of phase synchronization is based upon the weak coupling of two different systems, which can be analyzed using the concept of analytic signals as described in Cysarz et al. (2004) and Lackner et al. (2011). For this purpose, a phase (but not its amplitude) needs to be defined for a time series that contains oscillations in a narrow frequency band. To admit a clear physical interpretation, we used the Hilbert transform to compute the so-called discrete-time analytic signal $X_{D}$, with $X_{D}=X_{R}+i^{*} X_{I}$ such that $X_{I}$ is the Hilbert transform of the real vector $X_{R}$, from the band-pass filtered time series (in this case, the heart rates of the two partners of the dyad $\left[\mathrm{X}_{\mathrm{D} 1}, \mathrm{X}_{\mathrm{D} 2}\right]$ ). Subsequently, the phase of the resulting signals $\mathrm{X}_{\mathrm{D} 1}\left(\mathrm{t}_{\mathrm{i}}\right)$ and $\mathrm{X}_{\mathrm{D} 2}\left(\mathrm{t}_{\mathrm{i}}\right)$ at every time point $\mathrm{t}_{\mathrm{i}}$ was calculated. The time series are defined as synchronized if the phase difference $\Psi\left(\mathrm{t}_{\mathrm{i}}\right)$ is constant over time. In case of synchronization, the distribution of the phase difference, quantified by the synchronization index $\gamma=\left\{\cos \left(\Psi\left(\mathrm{t}_{\mathrm{i}}\right)\right)\right\}^{2}+\left\{\sin \left(\Psi\left(\mathrm{t}_{\mathrm{i}}\right)\right)\right\}^{2}$ (where curly brackets denote an average), shows a definite maximum. Theoretically, if the synchronization index $\gamma=1$, then both time series are completely synchronized in a statistical sense, while in the case of $\gamma=0$, both time series are completely desynchronized. Thus, the analysis of phase synchronization provides a quantitative indicator of the coordinated behavior of pairs of systems (i.e., in this case, the magnitude of heart rate synchrony of the two partners of a dyad) and is operationalized as a single synchrony variable for each couple; this variable serves as the primary study outcome. See Figure 1 for a graphical illustration of the computation of the synchronization index, using the example of the two conversation partners (CP1, CP2) of a dyad.

Given the fact that all participants in the recorded conversational dyads met for the first time at the beginning of the experiment, the first $7.5 \mathrm{~min}$ were used to allow the interpersonal alignment to develop, and the recording of the following $15 \mathrm{~min}$ was used for the analysis of heart rate synchrony. At the noticeable behavioral level, it was demonstrated that indicators of alignment between 

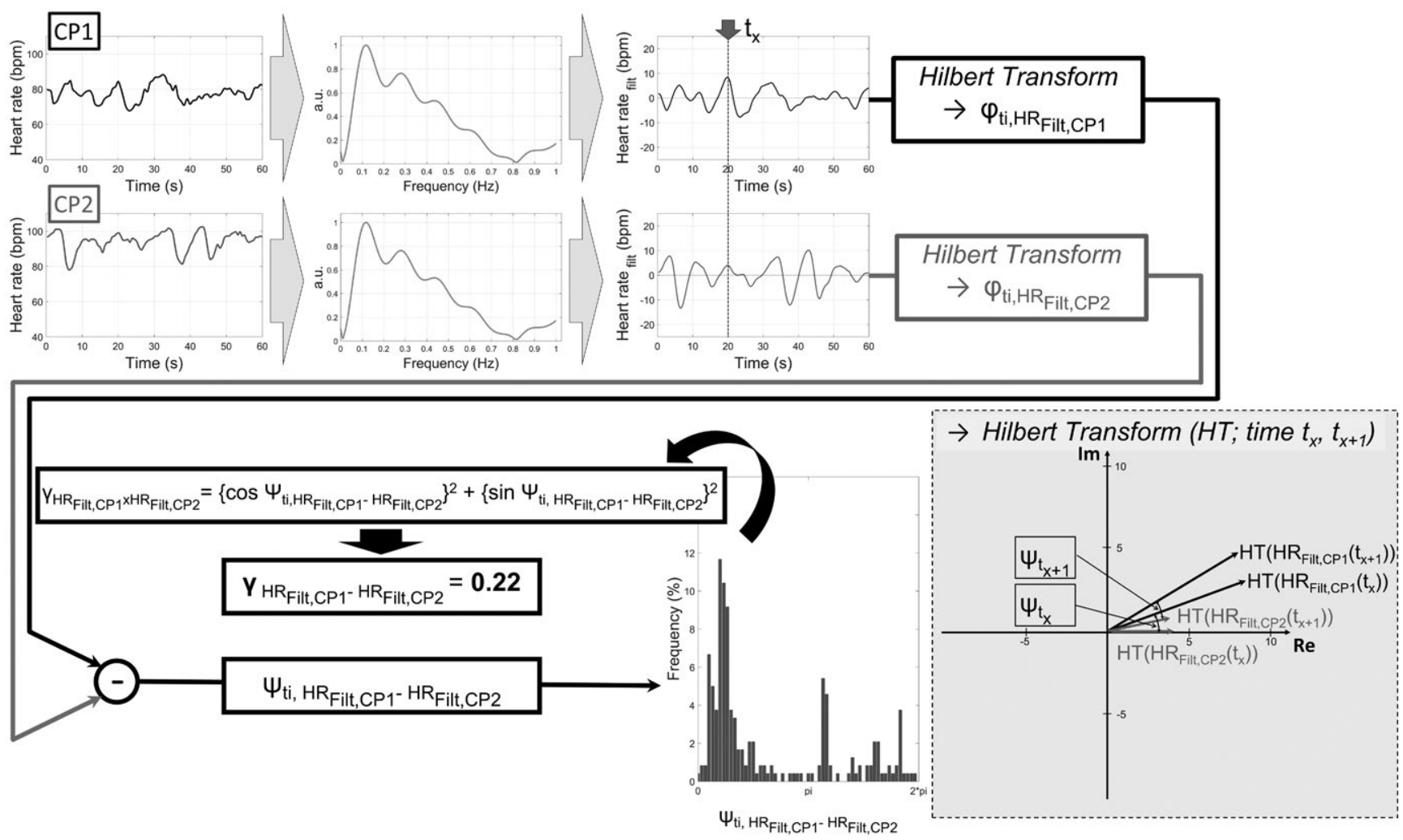

F I G U R E 1 Computation of the phase synchronization index. First, the raw signals of the two conversation partners (CP1, CP2) of a dyad (heart rate, first box on left), were band-pass filtered using a time domain filter (moving average filter to prevent frequency depending on phase shifts; the second box illustrates the filter characteristic), resulting in filtered heart rate time series $\left(\mathrm{HR}_{\text {filt }}\right.$, third box). The Hilbert transform was employed to calculate the phase of the filtered signals $\left(\varphi_{\mathrm{ti}}\right)$. Examples for the phase angles of CP1 (black) and CP2 (gray) at two specific time points $\left(t_{x}, t_{x+1}\right)$ are depicted in the gray shaded area on the right. $\Psi t_{x}$ and $\Psi t_{x+1}$ denote the phase differences between the HR time series of the two conversation partners at time points $t_{x}$ and $t_{x+1}$. The time point $t_{x}$ is indicated with an arrow in the third box above depicting the filtered heart rate. The distribution of all phase differences can be seen on the left of the gray shaded area in the lower part. In the final step, the phase differences $\Psi_{\mathrm{ti}}$ were used to quantify the phase synchronization $\gamma$ using the depicted formula, where the curly brackets $\{\ldots\}$ denote an average and $\mathrm{t}_{\mathrm{i}}$ the sample times. Theoretically, if the synchronization index $\gamma=1$, then the HR time series of two people are completely synchronized in a statistical sense, while in the case of $\gamma=0$, the time series are completely desynchronized. CP1, CP2 = conversation partners of a dyad; HR = heart rate; HT = Hilbert transform; $\varphi_{\mathrm{ti}}=$ phase angle of the time series at the time $\mathrm{t}_{\mathrm{i}} ; \Psi_{\mathrm{ti}}=$ phase difference; $\gamma=$ synchronization index

participants previously not known to each other increase with the inherent increase of familiarity and relatedness during the interaction (Feyaerts et al., 2017).

\section{4 | Recording of additional physiological variables}

A respiration belt was attached at the thoracic region to record the respiration curve (sampling rate $=32 \mathrm{~Hz}$ ). Additionally, a three-dimensional acceleration sensor (integrated in the ECG device) was used to record the participants' motor behavior. The respiration signal was band-pass filtered (frequency band: 0.05 $0.6 \mathrm{~Hz}$ ), the three acceleration signals were low-pass filtered (cutoff frequency: $4 \mathrm{~Hz}$ ). Afterward, the Cartesian coordinates of the three-dimensional acceleration sensor signal were transformed into spherical coordinates. Finally, as was done with the heart rate data, the respiration and motor behavior signals were resampled at $4 \mathrm{~Hz}$, respectively.

\subsection{Corpus and linguistic variables}

\subsection{1 | Amplifiers}

All 24 conversations were transcribed orthographically in ELAN, a professional tool for the creation of complex annotations on video and audio resources, developed at the Max Planck Institute for Psycholinguistics in Nijmegen, The Netherlands (Lausberg \& Sloetjes, 2009; Spiro \& Himberg, 2016). After the transcription, we used Frog (Van den Bosch, Busser, Daelemans, \& Canisius, 2007) to annotate the corpus for parts of speech (POS). This POS tagging allowed us to more easily query for verbal amplifiers. For example, if the Dutch word zot (English "crazy") is used as an adjective in zot meisje (English "crazy girl"), it should not be interpreted as an amplifier. However, if it occurs as an adverb in, for example, zot veel vrienden (English "crazy many friends"), it did qualify as an amplifier. We 
used the POS tags to more systematically query the corpus for the list of possible amplifiers we used. The corpus querying itself was done in ELAN. The following list of Flemish-Dutch verbal amplifiers were extracted from the corpus: dik, echt, erg, gemaan, heel, kei, kut, loos, mega, neig, ongelooflijk, super, totaal, waanzinnig, zot. On average, $M=22.8(S D=15.4 ; \min =2, \max =61)$ amplifiers were used in each dyadic conversation.

\subsection{2 | Comical hypotheticals}

For the quantification of comical hypotheticals, we counted at the level of intonation units: every intonation unit that was part of a comical hypothetical counted for one instance of the category "comical hypothetical." In the present study, we identify as "intonation unit" (e.g., Chafe, 1994; Halliday, 1989; Selting et al., 2009) the suprasegmental unit according to which segmentation of the spoken language can be made mainly depending on tone, or intonation. An intonation unit is identified as a functional unit with a cohesively experienced global pitch contour. By definition, each intonation unit also contains at least one stressed syllable, the so-called focal accent, which may be highlighted through either pitch movement and/or volume and/or phonetical length and which to a large extent determines the meaning of the expression. Apart from that, intonation units are delineated through the presence of one or more facultative border signals, such as (a) an intonational jump upward or downward at the unit's beginning or end, (b) higher speech rate during the first syllables leading up to the first accentuated syllable, (c) ultimate stretching at the unit's end, (d) creaky voice at the unit's end, (e) pitch movements on (un)accentuated syllables at the unit's end, and, finally, (f) pauses. On average, in each dyadic conversation, $M=9.6(S D=10.2 ; \min =0, \max =43)$, comical hypotheticals were identified. To increase the coding reliability, two experienced researchers specializing in cognitive linguistics jointly coded the data set: for every turn in the corpus, they jointly decided whether or not the turn met the definition of comical hypotheticals.

\subsection{3 | Degree of communicativeness}

The degree of communicativeness was quantified as percentage of time in which a participant was speaking. Scores for the two participants of a dyad were added to indicate the overall degree of communicativeness of a dyad $(M=61.48, S D=$ $23.50, \min =6.10, \max =91.52$ ). This index was considered the more reliable and valid index of communicativeness of a dyad compared to the total word count $(M=3,846.92, S D=$ $1,346.58, \min =443, \max =6,143)$, particularly in view of the quantification of comical hypotheticals in terms of intonation units.

\section{6 | FACS analysis}

Facial expressions were coded by two FACS-certified researchers using the Facial Action Coding System (Ekman et al., 2002). FACS provides an anatomically based, objective technique for the description of all observable facial movement in terms of action units (AU). The raters first identified all apexes of the participants' dynamic facial expressions. AUs were rated as present or absent in an apex according to the agreement of both raters, who were blind to the contents of speech (the sound track was removed from the videos). Apexes were later allocated to the linguistic elements. Apexes occurring in a time window of $2 \mathrm{~s}$ after a comical hypothetical or amplifier were considered as indicators of resonance of one conversation partner to the respective linguistic element used by the other person in a pair. The presence of AU 12 in an apex was used as a specific indicator for the reception and acknowledgment of humor in the communication elements. (AU 12 corresponds to action of the zygomaticus major muscle, which produces a smile). Inter-rater reliability estimates for the occurrence and timing of individual action units are good to excellent even when coded by a single coder (kappa coefficients for AU 12 range between 0.67 and 0.76; Sayette, Cohn, Wertz, Perrott, \& Parrot, 2001) and can be expected to be even higher when AUs are jointly coded by two experienced researchers. On average, a participant showed an apex (i.e., visible facial response) to $80.0 \%$ ( $S D=32.2$, $\mathrm{min}$ $=0, \max =100)$ of comical hypotheticals and $85.5 \%$ ( $S D=$ $38.8, \min =0, \max =100$ ) of amplifiers produced by his conversation partner. On average, $M=24.6 \%(S D=27.6$, min $=0, \max =100)$ of comical hypotheticals and $M=15 \%$ ( $S D$ $=15.3, \min =0, \max =50$ ) of amplifiers were followed by a display of AU 12 in the conversation partner.

\section{7 | Statistical analysis}

To confirm that the detected heart rate synchrony in actual dyads goes beyond spurious synchrony, heart rate synchrony in actual dyads was compared to surrogate data (paired $t$ test). As the phase synchronization index may be different from zero even in random pairs, comparing to surrogate data is superior to testing against zero in this case (cf. Lackner et al., 2011). Surrogate data were computed for each dyad by calculating the median of the synchronization indexes between each of the two partners of an actual dyad and all other participants in the sample excluding the actual conversation partner, respectively (i.e., $2 \times 46=92$ surrogate values for each dyad), which appropriately estimates the magnitude of the phase synchronization index between individuals not having any contact with each other.

The impact of the use of comical hypotheticals and verbal amplifiers in the dyadic conversations on heart rate synchrony was tested using one hierarchical multiple regression analysis 
each, with the magnitude of heart rate synchrony as the dependent variable. To evaluate the importance of the use of comical hypotheticals independently from the overall degree of communicativeness of a dyad (semipartial correlation $s r$ between number of comical hypotheticals and magnitude of heart rate synchrony), in the first step of the analysis of comical hypotheticals, the number of comical hypotheticals and the amount of speaking in a dyad were entered in the model. To evaluate whether additional variance was explained by the reception of humor in the comical hypotheticals produced by the conversation partner, beyond the overall number of produced comical hypotheticals in a dyad (Fchange/sr between the number of comical hypotheticals followed by AU 12 and magnitude of heart rate synchrony), in the second step, the number of comical hypotheticals that were followed by a smile (AU 12) of the conversation partner was entered. The impact of verbal amplifiers was tested in the same way. Additional analyses were done to evaluate the sensitivity and robustness of the findings.

\section{3 | RESULTS}

\subsection{Heart rate synchrony in conversation dyads}

Comparison with the surrogate data confirmed that heart rate synchrony in conversation dyads exceeded what would be expected by chance, $t(23)=4.3, p<0.001 ; d=0.88$; $M=0.14, S D=0.07 ; \min =0.04, \max =0.27$. See Figure 2 for a graphical representation of the frequency distribution of the heart rate synchrony scores (skewness $=0.47, S E=0.47$; kurtosis $=-0.65, S E=0.92$ ).

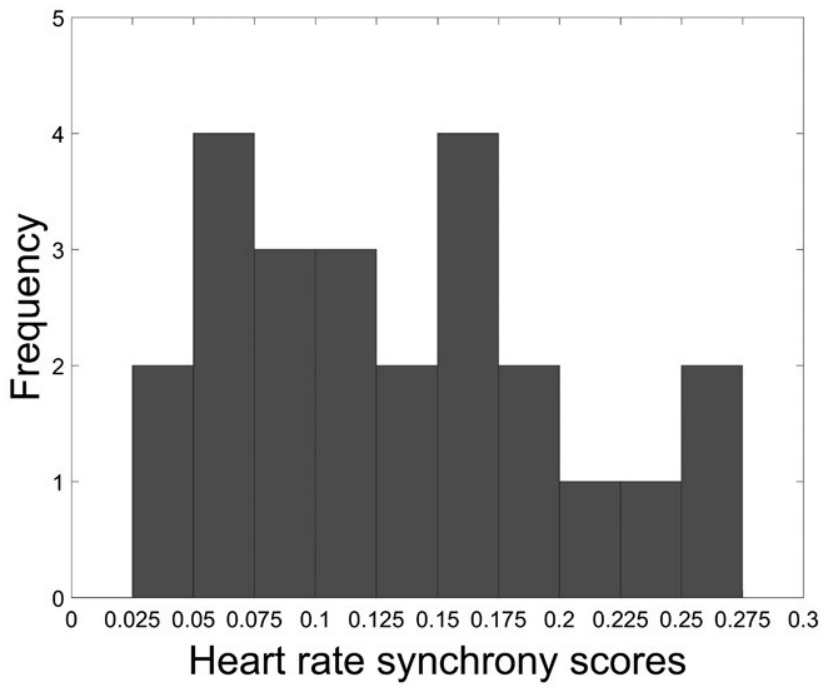

F I G U RE 2 Distribution of the heart rate synchrony scores

\section{2 | Impact of comical hypotheticals}

The analysis showed a correlation between the quantity of comical hypotheticals used by the two participants of a dyad and the magnitude of heart rate synchrony, independently of the global amount of speech production during the conversation: The more comical the hypotheticals produced in a dyad, the higher the magnitude of heart rate synchrony $\left(s r=0.52, t(21)=2.93, p=0.008 ; s r^{2}=0.27 ; F(2,21)=\right.$ $5.2, p=0.014)$. See Table 1 for a summary of the statistical results. The results further show that, while the zero-order correlation between the number of comical hypotheticals followed by a smile of the conversation partner and heart rate synchrony was also significant, $r(22)=0.43, p=0.036$, signals of the reception of humor in the comical hypotheticals of the conversation partner did not explain additional variance beyond the total production of comical hypotheticals in a dyad, Fchange $(1,20)=0.02, p=0.900$. This indicates that the effect on heart rate synchrony was produced by the use of comical hypotheticals as such and not only by those that were noticeably perceived as funny.

\section{3 | Impact of verbal amplifiers}

As opposed to comical hypotheticals, the total amount of verbal amplifiers used in a conversation did not correlate with the magnitude of heart rate synchrony, $r(22)=0.16$, $p=0.455 ; s r=0.01, t(21)=0.05, p=0.962 ; F(2,21)=$ $0.7, p=0.521$. However, the analysis revealed that a higher number of verbal amplifiers that had elicited a smile in the conversation partner was associated with a greater magnitude of heart rate synchrony, $r(22)=0.43, p=0.039 ; F$ change $(1$, $20)=6.2, p=0.021 ; s r^{2}=0.22$. See Table 2 for a summary of the statistical results.

\subsection{Ancillary analyses}

Several ancillary analyses were conducted to ensure the sensitivity and robustness of the study findings. To determine whether any facial resonance of the conversation partner had a similar effect as had signals of the reception of humor, analyses were done entering the overall number of apexes of facial expressions following comical hypotheticals/amplifiers produced by the conversation partner instead of the number of communication elements followed by smiles. They substantiated the primary conclusions. In the case of comical hypotheticals, the effect on heart rate synchrony was produced by the use of comical hypotheticals as such, and not only by those that elicited noticeable facial responses of the conversation partner. The effect of verbal amplifiers on heart rate synchrony is specifically attributed to signs of the reception of humor in the conversation partner but not to facial resonance of any kind. With several analyses, we 


\begin{tabular}{|cllllll|} 
Comical hypotheticals & $\boldsymbol{r}$ & $\boldsymbol{p}(\boldsymbol{r})$ & $\boldsymbol{s} \boldsymbol{r}$ & $\boldsymbol{p}(\boldsymbol{s} \boldsymbol{r})$ & $\boldsymbol{p}(\boldsymbol{F}) /(\boldsymbol{F c h a n g} \boldsymbol{e})$ \\
\hline Step 1 & Number of CH & $\mathbf{0 . 5 6}$ & 0.004 & $\mathbf{0 . 5 2}$ & 0.008 & 0.014 \\
\hline \multirow{2}{*}{ Step 2 } & Speaking & 0.25 & 0.248 & 0.13 & 0.491 & \\
& $\begin{array}{c}\text { Number of CH } \\
\text { followed by AU 12 }\end{array}$ & $\mathbf{0 . 4 3}$ & 0.036 & 0.02 & 0.900 & 0.900 \\
\hline
\end{tabular}

Note. $N=24$ dyads

Significant zero-order $(r)$ and semipartial $(s r)$ correlations are highlighted in bold font $(\alpha=0.05)$. $\mathrm{CH}=$ comical hypotheticals; $\mathrm{AU}=$ action units.

\begin{tabular}{|c|c|c|c|c|c|c|}
\hline \multicolumn{2}{|c|}{ Verbal amplifiers } & \multirow{2}{*}{$\begin{array}{l}r \\
0.16\end{array}$} & \multirow{2}{*}{$\begin{array}{l}\boldsymbol{p}(\boldsymbol{r}) \\
0.455\end{array}$} & \multirow{2}{*}{$\begin{array}{l}\boldsymbol{s r} \\
0.01\end{array}$} & \multirow{2}{*}{$\begin{array}{l}\boldsymbol{p}(\boldsymbol{s} \boldsymbol{r}) \\
0.962\end{array}$} & \multirow{2}{*}{$\begin{array}{l}\boldsymbol{p}(\boldsymbol{F}) /(\text { Fchange }) \\
0.521\end{array}$} \\
\hline Step 1 & Number of VA & & & & & \\
\hline & Speaking & 0.24 & 0.248 & 0.19 & 0.390 & \\
\hline Step 2 & $\begin{array}{l}\text { Number of VA } \\
\text { followed by AU } 12\end{array}$ & 0.43 & 0.039 & 0.47 & 0.021 & 0.021 \\
\hline
\end{tabular}

Note. $N=24$ dyads

Significant zero-order $(r)$ and semipartial $(s r)$ correlations are highlighted in bold font $(\alpha=0.05)$. VA $=$ verbal amplifiers; $\mathrm{AU}=$ action units.
TA B LE 1 Impact of the use of comical hypotheticals in dyadic conversations on the magnitude of heart rate synchrony
T A B LE 2 Impact of the use of verbal amplifiers in dyadic conversations on the magnitude of heart rate synchrony examined if the effects on heart rate synchrony may have been driven by synchronized respiration patterns or matched motor behavior. These analyses confirmed that the observed effects are genuine cardiac effects. The findings remained robust when the two main multiple regression analyses were recalculated using the total word count instead of the timebased index of communicativeness as described in Section 2.5. Nonparametric correlations and a comprehensive check for outliers gave no indications of distribution irregularities. Finally, it was confirmed that changes of mood did not play a role in this study. Details of these ancillary analyses can be found in the online supporting information to this article.

\section{4 | DISCUSSION}

The present study investigated heart rate synchrony in male dyads whose members did not previously know each other during natural, spontaneous conversations. We found that the heart rate time series of the two conversation partners were to some extent synchronized in phase, and that the magnitude of this synchronization exceeded chance levels. Moreover, novel to the field of interpersonal physiological synchrony, it was demonstrated that the strength of heart rate synchrony between the members of a dyad was influenced by specific linguistic features of the ongoing dialogue.

Phasic changes of heart rate mirror the adaptations of a sensitive, flexible, and rapidly responding central autonomic system. Consequently, the degree of phase synchronization maps the degree of moment-to-moment adjustments that occur between the two persons of a dyad. Important to note, the degree of phase synchronization is determined by the temporal synchronization of the variations in the heart rates of the conversation partners only. Changes in tonic heart rate levels or differences in the amplitudes of fluctuations do not influence the phase synchronization index (unlike, for instance, in cross-correlation and similar approaches). This should make the method relatively robust against interfering influences, because situational, personal, or physiological factors that change the tonic heart rate level of one interlocutor, or that are linked with the amplitude of fluctuations, do not affect the magnitude of heart rate synchrony. Moreover, with the priority on the synchrony of changes over time and not on the harmonization of the two interaction partners' cardiac activity as such, this approach seems more relevant in view of the mutual adaptation in support of the envisaged joint understanding that is inherent in dyadic conversations (Clark, 1996; Feyaerts \& Oben, 2014; Verhagen, 2015).

There was no indication that the observed heart rate synchrony may have been driven by more simple physiological processes such as matched breathing. Heart rate acceleration during inhalation and deceleration during exhalation (respiratory sinus arrhythmia) can cause fast variations in the heart rate, which may produce spurious heart rate synchrony when the breathing cycles of the two interaction partners are synchronized. This mechanism is most obvious in choir singing where the respiratory patterns of the singers are naturally highly synchronized, which increases cardiac synchrony by virtue of the respiratory sinus arrhythmia (Hemakom, Powezka, Goverdovsky, Jaffer, \& Mandic, 2017; Müller \& Lindenberger, 2011). Speaking is also associated with altered respiratory patterns (Hoit \& Lohmeier, 2000). However, this 
should not spuriously augment heart rate synchrony, because the two partners of a conversation typically do not speak in unison. Descriptive analyses of breathing patterns during spontaneous dyadic conversation suggested that the breathing pattern while listening may mirror the speech pattern of the conversation partner (McFarland, 2001), but this was also not observed in the present data.

Shared metabolic demands through matched behavior may also augment the magnitude of heart rate synchrony between two interaction partners. Hand and finger movements are accompanied by phasic heart rate changes (Florian, Stancak, $\&$ Pfurtscheller, 1998) and thus may produce spurious heart rate synchrony when carried out simultaneously by both interaction partners. However, in the present data, joint movements could be excluded as a driver of heart rate synchrony. More gross movements and changes in activity levels were precluded from the outset by having the participants remain seated during the entire dialogue. The influence of synchronized small movements was ruled out by analyzing the data of the motion sensors.

Thus, in the present experimental setting, matched breathing and motor behavior do not seem to be root causes of heart rate synchrony. It seems most likely that the observed heart rate synchrony originates from mutual mental alignment during the conversation, which produces small variations in the heart rate through autonomic nervous system influences that are mirrored in the conversation partner. While there is no way to directly validate this notion, the influence of psychosocial processes of this kind is suggested by the observed associations between the strength of heart rate synchrony between the interlocutors and linguistic features of the ongoing dialogue. Specifically, the magnitude of heart rate synchrony was correlated with the quantities of humor-related communication elements used in the conversations. The strength of heart rate synchrony in a dyad was higher the more comical hypotheticals were produced, independently from the total amount of conversation among the interlocutors. A similar observation was made for verbal amplifiers, but their effect depended on the question whether they were received (and acknowledged by a smile) as humorous. This is plausible insofar as humor and personal involvement are inherent characteristics of comical hypotheticals as such. They represent a powerful type of interactional humor, and resonance of the interaction partner is already anticipated in the production of comical hypotheticals (Feyaerts, 2013; Winchatz \& Kozin, 2008). In contrast, verbal amplifiers are often used in a humorous way (Hancock, 2004), but this is not necessarily always the case. It should be noted that effect sizes were considerable in these relationships. The amount of comical hypotheticals and verbal amplifiers followed by smiles of the conversation partner explained around $25 \%$ of the variance of the magnitude of heart rate synchrony in a dyad, respectively. The correlations surely benefited from the used experimental design in which the conversation was not constrained by a joint task or specific goal, thus allowing much space for variability in the dialogues, including humorous components.

On a broader perspective, the findings of the present study are in line with the idea that physiological synchrony may be enhanced by shared experience (Palumbo et al., 2017). The use of humor in a dyadic conversation implies communalities in the interlocutors' construals (Flamson \& Barrett, 2008). It reveals an attempt to establish and elaborate interactional common ground (Clark, 1996), which may facilitate getting acquainted and advance the interpersonal alignment of viewpoints (Curry \& Dunbar, 2013; Zeigler-Hill, Besser, \& Jett, 2013). Thereby, feelings of connectedness and closeness as well as the interlocutors' involvement in the dialogue are augmented, all of which have been reported to be associated with shared humor (Curry \& Dunbar, 2013; Fraley \& Aaron, 2004; Kashdan et al., 2014; Kurtz \& Algoe, 2015, Li et al., 2009; Weisfeld, 1993). It was also shown more specifically that interaction partners felt more at ease in the conversation and closer to one another when more comical hypotheticals and verbal amplifiers were used in a dialogue (Feyaerts et al., 2017)

At the same time, the comprehension and appreciation of humor requires cognitive effort. It involves, for instance, viewing what is originally perceived in one (often serious) sense from a different perspective, in order to resolve the surprising incongruity by consideration of past or contextual information (Martin, 2007; Ruch, 2001; Suls, 1972). In more complex forms of humor, mechanisms of layered meaning processing (Clark, 1996) such as mentalizing and anticipation of events that are only insinuated, are often additionally involved (Weiss et al., 2013). Consequently, the use of humor may pose additional demands on the collaborative effort to establish a joint understanding of the conversational content, which is inherent in every dyadic conversation (Clark, 1996; Feyaerts \& Oben, 2014; Verhagen, 2015). This should additionally increase the interlocutors' involvement in a dialogue incorporating shared humor. The idea of shared experience as the crucial process underlying heart rate synchrony in conversational dyads is also corroborated by the psychological processes that are reflected in phasic variations of heart rate such as subtle changes of emotional arousal and motivational states (e.g., Bradley et al., 2001; Gunther Moor et al., 2010; Lackner et al., 2013; Papousek, Aydin, et al., 2014; Papousek, Weiss, et al., 2014; Wright \& Gendolla, 2012).

This study has several limitations. Notwithstanding several efforts to strengthen the reliability of the measures and to confirm the specificity and robustness of the findings, the sample size is at the lower limit, explained by the extremely time consuming and demanding data analysis (linguistic and FACS coding), which made a larger sample unfeasible. Consequently, replication of the findings will be important, preferably with slightly varying methods. Another 
limitation is that only male dyads were tested, which may allow generalization of the findings to women to a limited extent only. In this context, it also seems important to note that other or additional processes may play a role in mixed gender dyads, which may be associated with evolutionary functions of humor such as mate attraction (e.g., Hone, Hurwitz, \& Lieberman, 2015; Li et al., 2009). A further limitation of the current research may be that more comprehensive mathematical analyses of dyadic physiological data might explain additional portions of variance of the physiological synchrony between individuals (see, e.g., Guastello, 2016). However, the relative simplicity of phase synchronization is also an advantage, especially in regard to the straightforward interpretation of its magnitude. Finally, as a future prospect, it will be an exciting endeavor to expand this research to larger groups.

In conclusion, by illustrating the effect of using humorrelated communication elements, the present study adds a piece to the puzzle of which conditions facilitate heart rate synchrony between two conversation partners who are meeting for the first time. In view of the importance that is attached to the magnitude of interpersonal physiological synchrony in terms of states of relationships (for review, see, e.g., Palumbo et al., 2017), the findings suggest that the use of (reciprocated) humor may speed up the building of rapport among communication partners. The process might be profitably employed in encounters where the fast establishment of a good communication basis is desirable, for instance, in psychotherapy or in collaborative teams.

\section{ORCID}

Helmut K. Lackner (iD) https://orcid.org/0000-0002-0159-3720 Andreas Schwerdtfeger (D) https://orcid.org/0000-0002-0371-3730 Ilona Papousek (iD https://orcid.org/0000-0002-6620-0318

\section{REFERENCES}

Athanasiadou, A. (2007). On the subjectivity of intensifiers. Language Sciences, 29, 554-565. https://doi.org/10.1016/j. langsci.2007.01.009

Binz, U., \& Wendt, G. (1986). KUSTA-Kurz-Skala Stimmung/ Aktivierung [Brief rating scale Mood/Arousal). In Collegium Internationale Psychiatriae Scalarum (3rd ed, pp. 131-135). Internationale Skalen für Psychiatrie [International rating scales for psychiatry.] Weinheim, Germany: Beltz.

Bradley, M. M., Codispoti, M., Cuthbert, B. N., \& Lang, P. J. (2001). Emotion and motivation I: Defensive and appetitive reactions in picture processing. Emotion, 1, 276-298. https://doi. org/10.1037//1528-3542.1.3.276

Breindl, E. (2007). Intensitätspartikel. In L. Hoffmann (Ed.), Handbuch der deutschen Wortarten [Handbook of German word classes] (pp. 397-422). Berlin, Germany: De Gruyter.
Brennan, S. E., \& Clark, H. (1996). Conceptual pacts and lexical choice in conversation. Journal of Experimental Psychology: Learning, Memory, and Cognition, 22, 1482-1493. https://doi. org/10.1037/0278-7393.22.6.1482

Chafe, W. (1994). Discourse, consciousness, and time: The flow and displacement of conscious experience in speaking and writing. Chicago, IL University of Chicago Press.

Chanel, G., Kivikangas, J., \& Ravaja, N. (2012). Physiological compliance for social gaming analysis: Cooperative versus competitive play. Interacting with Computers, 24, 306-316. https:// doi.org/10.1016/j.intcom.2012.04.012

Chartrand, T. L., \& Lakin, J. L. (2013). The antecedents and consequences of human behavioral mimicry. Annual Reviews of Psychology, 64, 285-308. https://doi.org/10.1146/annurev-psych-113011-143754

Clark, H. H. (1996). Using language. Cambridge, UK: Cambridge University Press. https://doi.org/10.1017/CBO9780511620539

Coleman, R., Greenblatt, M., \& Solomon, H. C. (1956). Physiological evidence of rapport during psychotherapeutic interviews. Diseases of the Nervous System, 17, 71-77.

Curry, O. S., \& Dunbar, R. I. (2013). Sharing a joke: The effects of a similar sense of humor on affiliation and altruism. Evolution and Human Behavior, 34, 125-129. https://doi.org/10.1016/j. evolhumbehav.2012.11.003

Cysarz, D., von Bonin, D., Lackner, H., Heusser, P., Moser, M., \& Bettermann, H. (2004). Oscillations of heart rate and respiration synchronize during poetry recitation. American Journal of Physiology Heart and Circulatory Physiology, 287, H579-H587. https://doi. org/10.1152/ajpheart.01131.2003

Ekman, P., Friesen, W. V., \& Hager, J. C. (2002). Facial Action Coding System: A technique for the measurement of facial movement. Palo Alto, CA: Consulting Psychologists Press.

Feldman, R., Magori-Cohen, R., Galili, G., Singer, M., \& Louzon, Y. (2011). Mother and infant coordinate heart rhythms through episodes of interaction synchrony. Infant Behavior and Development, 34, 569-577. https://doi.org/10.1016/j.infbeh.2011.06.008

Ferrer, E., \& Helm, J. L. (2013). Dynamical systems modeling of physiological coregulation in dyadic interactions. International Journal of Psychophysiology, 88, 296-308. https://doi.org/10.1016/j. ijpsycho.2012.10.013

Feyaerts, K. (2013). Tackling the complexity of spontaneous humorous interaction. An integrated-classroom modeled corpus approach. In L. R. Gurillo \& M. B. A. Ortega (Eds.), Irony and humor. From pragmatics to discourse (pp. 243-268). Amsterdam, The Netherlands: John Benjamins. https://doi.org/10.1075/ pbns.231.14fey

Feyaerts, K., \& Oben, B. (2014). Tracing down schadenfreude in spontaneous interaction. Evidence from corpus linguistics. In W. Van Dijk \& J. W. Ouwerkerk (Eds.), 'Schadenfreude': Understanding pleasure at the misfortune of others (pp. 275-291). Cambridge, UK: Cambridge University Press. https://doi.org/10.1017/ CBO9781139084246.023

Feyaerts, K., Oben, B., Lackner, H. K., \& Papousek, I. (2017). Alignment and empathy as viewpoint phenomena: The case of amplifiers and comical hypotheticals. Cognitive Linguistics, 28, 485-509. https:// doi.org/10.1515/cog-2016-0109

Field, T., Healy, B., \& LeBlanc, W. (1989). Sharing and synchrony of behavior states and heart rate in nondepressed versus depressed mother-infant interactions. Infant Behavior and Development, 12, 357-376. https://doi.org/10.1016/0163-6383(89)90044-1 
Flamson, T., \& Barrett, H. (2008). The encryption theory of humor: A knowledge-based mechanism of honest signaling. Journal of Evolutionary Psychology, 6, 261-281. https://doi.org/10.1556/ JEP.6.2008.4.2

Florian, G., Stancak, A., \& Pfurtscheller, G. (1998). Cardiac response induced by voluntary self-paced finger movement. International Journal of Psychophysiology, 28, 273-283. https://doi.org/10.1016/ S0167-8760(97)00075-5

Fraley, B., \& Aron, A. (2004). The effect of a shared humorous experience on closeness in initial encounters. Personal Relationships, 11, 61-78. https://doi.org/10.1111/j.1475-6811.2004.00071.x

Garrod, S., \& Pickering, M. J. (2004). Why is conversation so easy? Trends in Cognitive Science, 8, 8-11. 10-1016/j.tics.2003.10.016

Goldberger, J. J. (1999). Sympathovagal balance: How should we measure it. American Journal of Physiology, 276, H1273-H1280. https://doi.org/10.1152/ajpheart.1999.276.4.H1273

Goldstein, P., Weissman-Fogel, I., \& Shamay-Tsoory, S. G. (2017). The role of touch in regulating inter-partner physiological coupling during empathy for pain. Scientific Reports, 7, 3252. https://doi. org/10.1038/s41598-017-03627-7

Gorisch, J., Wells, B., \& Brown, G. J. (2012). Pitch contour matching and interactional alignment across turns: An acoustic investigation. Language and Speech, 55, 57-76. https://doi.org/10.1177/00238309 11428874

Gries, S. (2005). Syntactic priming: A corpus-based approach. Journal of Psycholinguistic Research, 34, 365-399. https://doi.org/10.1007/ s10936-005-6139-3

Guastello, S. J. (2016). Physiological synchronization in a vigilance dual task. Nonlinear Dynamics, Psychology, and Life Sciences, 20, 49-80.

Gunther Moor, B. G., Crone, E. A., \& van der Molen, M. W. (2010). The heartbrake of social rejection: Heart rate deceleration in response to unexpected peer rejection. Psychological Science, 21, 1326-1333. https://doi.org/10.1177/0956797610379236

Gutzmann, D., \& Turgay, K. (2012). Expressive intensifiers in German: Syntax-semantics mismatches. In C. Pinon (Ed.), Empirical issues in syntax and semantics, 9, 146-166.

Halliday, M. A. K. (1989). Spoken and written language (2nd ed.). Oxford, UK: Oxford University Press.

Hancock, J. T. (2004). Verbal irony use in computer-mediated and faceto-face conversations. Journal of Language and Social Psychology, 23, 447-463. https://doi.org/10.1177/0261927X04269587

Helm, J. L., Sbarra, D., \& Ferrer, E. (2012). Assessing cross-partner associations in physiological responses via coupled oscillator models. Emotion, 12, 748-762. https://doi.org/10.1037/a0025036

Hemakom, A., Powezka, K., Goverdovsky, V., Jaffer, U., \& Mandic, D. (2017). Quantifying team cooperation through intrinsic multi-scale measures: Respiratory and cardiac synchronization in choir singers and surgical teams. Royal Society Open Science, 4, 170853. https:// doi.org/10.1098/rsos.170853

Henning, R. A., Boucsein, W., \& Gil, M. C. (2001). Social-physiological compliance as a determinant of team performance. International Journal of Psychophysiology, 40, 221-232. https://doi.org/10.1016/ S0167-8760(00)00190-2

Henning, R. A., \& Korbelak, K. T. (2005). Social-psychophysiological compliance as a predictor of future team performance. Psychologia: An International Journal of Psychology in the Orient, 48, 84-92. https://doi.org/10.2117/psysoc.2005.84

Hoit, J. D., \& Lohmeier, H. L. (2000). Influence of continuous speaking on ventilation. Journal of Speech, Language and Hearing Research, 43, 1240-1251. https://doi.org/10.1044/jslhr.4305.1240
Holler, J., \& Wilkin, K. (2011). Co-speech gesture mimicry in the process of collaborative referring during face-to-face dialogue. Journal of Nonverbal Behavior, 35, 133-153. https://doi.org/10.1007/ s10919-011-0105-6

Hone, L. S., Hurwitz, W., \& Lieberman, D. (2015). Sex differences in preferences for humor: A replication, modification, and extension. Evolutionary Psychology, 13, 167-181. https://doi. org/10.1177/147470491501300110

Järvelä, S., Kivikangas, J. M., Kätsyri, J., \& Ravaja, N. (2013). Physiological linkage of dyadic gaming experience. Simulation and Gaming, 45, 24-40. https://doi.org/10.1177/1046878113513080

Kashdan, T. B., Yarbro, J., McKnight, P. E., \& Nezlek, J. B. (2014). Laughter with someone else leads to future social rewards: Temporal change using experience sampling methodology. Personality and Individual Differences, 58, 15-19. https://doi.org/10.1016/j. paid.2013.09.025

Kurtz, L. E., \& Algoe, S. B. (2015). Putting laughter in context: Shared laughter as behavioral indicator of relationship well-being. Personal Relationships, 22, 573-590. https://doi.org/10.1111/pere.12095

Lackner, H. K., Batzel, J. J., Rössler, A., Hinghofer-Szalkay, H., \& Papousek, I. (2014). Multi-time scale perspective in analyzing cardiovascular data. Physiological Research, 63, 439-456.

Lackner, H. K., Papousek, I., Batzel, J. J., Roessler, A., Scharfetter, H., \& Hinghofer-Szalkay, H. (2011). Phase synchronization of hemodynamic variables and respiration during mental challenge. International Journal of Psychophysiology, 79, 401-409. https:// doi.org/10.1016/j.ijpsycho.2011.01.001

Lackner, H. K., Weiss, E. M., Schulter, G., Hinghofer-Szalkay, H., Samson, A. C., \& Papousek, I. (2013). I got it! Transient cardiovascular response to the perception of humor. Biological Psychology, 93, 33-40. https://doi.org/10.1016/j.biopsycho.2013.01.014

Lausberg, H., \& Sloetjes, H. (2009). Coding gestural behavior with the NEUROGES-ELAN system. Behavior Research Methods, Instruments and Computers, 41, 841-849. https://doi.org/10.3758/ BRM.41.3.841

Levenson, R. W., \& Gottman,J.M.(1983). Maritalinteraction:Physiological linkage and affective exchange. Journal of Personality and Social Psychology, 45, 587-597. https://doi.org/10.1037/0022-3514.45.3.587

Li, N. P., Griskevicius, V., Durante, K. M., Jonason, P. K., Pasisz, D. J., \& Aumer, K. (2009). An evolutionary perspective on humor: Sexual selection or interest indication? Personality and Social Psychology Bulletin, 35, 923-936. https://doi.org/10.1177/0146167209334786

Martin, R. A. (2007). Approaches to the sense of humor: A historical review. In W. Ruch (Ed.), The sense of humor: Explorations of a personality characteristic (pp. 15-60). Berlin, Germany: Mouton de Gruyter. https://doi.org/10.1515/9783110804607-004

McFarland, D. H. (2001). Respiratory markers of conversational interaction. Journal of Speech, Language, and Hearing Research, 44, 128-143. https://doi.org/10.1044/1092-4388(2001/012)

Mitkidis, P., McGraw, J. J., Roepstorff, A., \& Wallot, S. (2015). Building trust: Heart rate synchrony and arousal during joint action increased by public goods game. Physiology and Behavior, 149, 101-106. https://doi.org/10.1016/j.physbeh.2015.05.033

Muhtadie, L., Akinola, M., Koslov, K., \& Mendes, W. B. (2015). Vagal flexibility: A physiological predictor of social sensitivity. Journal of Personality and Social Psychology, 109, 106-120. https://doi. org/10.1037/pspp0000016

Müller, V., \& Lindenberger, U. (2011). Cardiac and respiratory patterns synchronize between persons during choir singing. PLOS ONE, 6, e24893. https://doi.org/10.1371/journal.pone.0024893 
Oben, B., \& Brône, G. (2015). What you see is what you do: On the relationship between gaze and gesture in multimodal alignment. Language and Cognition, 7, 546-562. https://doi.org/10.1017/ langcog.2015.22

Oben, B., \& Brône, G. (2016). Explaining interactive alignment: A multimodal and multifactorial account. Journal of Pragmatics, 104, 32-51. https://doi.org/10.1016/j.pragma.2016.07.002

Palumbo, R. V., Marraccini, M. E., Weyandt, L. L., Wilder-Smith, O., McGee, H. A., Liu, S., \& Goodwin, M. S. (2017). Interpersonal autonomic physiology: A systematic review of the literature. Personality and Social Psychology Review, 21, 99-141. https://doi. org/10.1177/1088868316628405

Papousek, I., Weiss, E. M., Schulter, G., Fink, A., Reiser, E. M., \& Lackner, H. K. (2014). Prefrontal EEG alpha asymmetry changes while observing disaster happening to other people: Cardiac correlates and prediction of emotional impact. Biological Psychology, 103, 184-194. https://doi. org/10.1016/j.biopsycho.2014.09.001

Papousek, I., Aydin, N., Lackner, H. K., Weiss, E. M., Bühner, M., Schulter, G., ... Freudenthaler, H. H. (2014). Laughter as a social rejection cue: Gelotophobia and transient cardiac responses to other persons' laugher and insult. Psychophysiology, 51, 1112-1121. https://doi.org/10.1111/psyp.12259

Pardo, J. S. (2006). On phonetic convergence during conversational interaction. Journal of the Acoustic Society of America, 119, 23822393. https://doi.org/10.1121/1.2178720

Paxton, A., \& Dale, R. (2013). Frame differencing methods for measuring bodily synchrony in conversation. Behavior Research Methods 45, 329-343. https://doi.org/10.3758/s13428-012-0249-2

Richardson, D., \& Dale, R. (2005). Looking to understand: The coupling between speakers' and listeners' eye movements and its relationship to discourse comprehension. Cognitive Science, 29, 1045-1060. https://doi.org/10.1207/s15516709cog0000_29

Ruch, W. (2001). The perception of humor. In A. W. Kaszniak (Ed.), Emotion, qualia, and consciousness (pp. 410-425). Tokyo, Japan: Word Scientific Publisher. https://doi. org/10.1142/9789812810687_0032

Sato, N., \& Miyake, S. (2004). Cardiovascular reactivity to mental stress: Relationship with menstrual cycle and gender. Journal of Physiological Anthropology and Applied Human Science, 23, 215223. https://doi.org/10.2114/jpa.23.215

Sayette, M. A., Cohn, J. F., Wertz, J. M., Perrott, M. A., \& Parrott, D. J. (2001). A psychometric evaluation of the facial action coding system for assessing spontaneous expression. Journal of Nonverbal Behavior, 25, 167-185. https://doi. org/10.1023/A:1010671109788

Selting, M., Auer, P., Barth-Weingarten, D., Bergmann, J., Bergmann, P., Birkner, K., ... Uhmann, S. (2009). Gesprächsanalytisches Transkriptionssystem 2 (GAT 2). [Conversation Analytic Transcription System 2 (GAT2)]. Gesprächsforschung-OnlineZeitschrift zur verbalen Interaktion, 10, 353-402.

Spiro, N., \& Himberg, T. (2016). Analysing change in music therapy interactions of children with communication difficulties. Philosophical Transactions of the Royal Society B: Biological Sciences, 5, 371. https://doi.org/10.1098/rstb.2015.0374

Suls, J. M. (1972). A two-stage model for the appreciation of jokes and cartoons: An information processing analysis. In J. H Goldstein \& P. E. McGhee (Eds.), The psychology of humor (pp. 81-100). New York, NY: Academic Press. https://doi. org/10.1016/B978-0-12-288950-9.50010-9

Suveg, C., Shaffer, A., \& Daavis, M. (2016). Family stress moderates relations between physiological and behavioral synchrony and child self-regulation in mother-preschooler dyads. Developmental Psychobiology, 58, 83-97. https://doi.org/10.1002/dev.21358

Tenan, M. S., Brothers, R. M., Tweedell, A. J., Hackney, A. C., \& Griffin, L. (2014). Changes in resting heart rate variability across the menstrual cycle. Psychophysiology, 51, 996-1004. https://doi. org/10.1111/psyp. 12250

Van den Bosch, A., Busser, B., Daelemans, W., \& Canisius, S. (2007). An efficient memory-based morphosyntactic tagger and parser for Dutch. Selected Papers of the 17th Computational Linguistics in the Netherlands Meeting, Leuven, Belgium. (pp. 99-114).

Verhagen, A. (2015). Grammar and cooperative communication. In E. Dabrowska \& D. Divjak (Eds.), Handbook of cognitive linguistics (pp. 232-252). Berlin, Germany: Mouton De Gruyter. https://doi. org/10.1515/9783110292022-012

Weisfeld, G. E. (1993). The adaptive value of humor and laughter. Ethology and Sociobiology, 14, 141-169. https://doi. org/10.1016/0162-3095(93)90012-7

Weiss, E. M., Gschaidbauer, B. C., Samson, A. C., Steinbäcker, K., Fink, A., \& Papousek, I. (2013). From Ice Age to Madagascar: Appreciation of slapstick humor in children with Asperger's syndrome. Humor: International Journal of Humor Research, 26, $423-$ 440. https://doi.org/10.1515/humor-2013-0029

Winchatz, M., \& Kozin, A. (2008). Comical hypothetical: Arguing for a conversational phenomenon. Discourse Studies, 10, 383-405. https://doi.org/10.1177/1461445608089917

Woltering, S., Lishak, V., Elliott, B., Ferraro, L., \& Granic, I. (2015). Dyadic attunement and physiological synchrony during motherchild interactions: An exploratory study in children with and without externalizing behavior problems. Journal of Psychopathology and Behavioral Assessment, 37, 624-633. https://doi.org/10.1007/ s10862-015-9480-3

Wright, R. A., \& Gendolla, G. H. E. (2012). How motivation affects cardiovascular response mechanisms and applications. Washington, DC: APA Press. https://doi.org/10.1037/13090-000

Zeigler-Hill, V., Besser, A., \& Jett, S. E. (2013). Laughing at the looking glass: Does humor style serve as an interpersonal signal? Evolutionary Psychology, 11, 201-226. https://doi. org/10.1177/147470491301100118

\section{SUPPORTING INFORMATION}

Additional supporting information may be found online in the Supporting Information section at the end of the article.

How to cite this article: Lackner HK, Feyaerts K, Rominger C, Oben B, Schwerdtfeger A, Papousek I. Impact of humor-related communication elements in natural dyadic interactions on interpersonal physiological synchrony. Psychophysiology. 2019;e13320. https://doi.org/10.1111/psyp.13320 